le posizioni dell'autore sulle responsabilita di un'Europa disunita che porto' prima alla disintegrazione del paese, poi all'intervento NATO e infine all'inizio di una nuova era di egemonia americana incontrastata.

In generale Gallagher analizza brillantemente i calcoli miopi di alcune potenze occidentali, alle quali andrebbe aggiunta l'Italia (p. 57). Forse piu' spazio potrebbe essere stato assegnato al ruolo iniziale svolto dalla prima amministrazione Bush. Agli inizi del conflitto, gli USA rifiutarono deliberatamente di affrontare Milosevic lasciando il gioco interamente in mano degli europei (ed in particolare del governo conservatore inglese), ben sapendo che le divisioni interne europee avrebbero richiesto prima o dopo un massiccio intervento americano. Ma affinche' il governo americano potesse intervenire, la situazione sarebbe dovuta prima precipitare fino ad apparire una minaccia sostanziale alla sicurezza internazionale. Il desiderio americano di 'ridimensionare' (se non distruggere) l'Europa all' indomani del trattato di Maastritch, fomentando nazionalismi e statalismi rivali, ha potuto realizzarsi attraverso un' appoggio surrettizio al regime di Milosevic. Nonostante le retoriche incrociate, Milosevic vide infatti premiate le sue scelte: con gli accordi di Dayton, Ohio, gli USA riconoscevano sia il ruolo di Milosevic come autorevole interlocutore e 'mediatore, sia la partizio- ne della Bosnia. Tale punto potrebbe essere stato sviluppato ulteriormente in una piu' ampia spiegazione della crisi americana del dopo-'guerra fredda', nel cui corso l'Unione Europea fu lentamente emarginata e perse la credibilita internazionale, rendendo le democrazie atlantiche sempre piu' dipendenti dalla NATO. Infine l'attacco NATO alla Jugoslavia segnalo' il collasso di una comune ed indipendente politica di sicurezza europea. Cio' contribui all'espansione senza freni del capitalismo 'made in USA' in tutte le societa' postcomuniste, dai Balcani alla Russia. Sfortunatamente, non esiste ancora un libro che affronti la crisi balcanica da una prospettiva storica trans-atlantica credibile, probabilmente perche' la storia si sta ancora formando nel momento stesso in cui scriviamo.

L'importanza di questo libro ne rende una traduzione al catalano/spagnolo piu' che opportuna. In breve, si tratta di un' libro eccellente, ben argomentato, solido e coerente che, insieme con quello Simms', dovrebbe trasformarsi in uno strumento di consultazione obbligatoria per tutti coloro che si occupano dell'ex Jugoslavia e delle societa' post-comuniste in generale.

\section{Dr. Daniele Conversi} University of Lincoln Department of Policy Studies conversi@easynet.co.uk

\title{
DONATI, Pierpalo
}

\section{Manual de sociología de la familia}

(traducción y revisión técnica de Manuel Herrera y Sonia Pagés)

Pamplona: EUNSA, 2003, 452 p.

El presente volumen pretende ser un instrumento para conocer, analizar e interpretar los cambios y las transformaciones que registra la familia en la sociedad actual. La particularidad de este Manual de sociología de la familia se encuentra en el enfoque utilizado por el autor, la perspectiva relacional. Pierpaolo Donati, profesor ordinario de Sociología de la Universidad de Bolonia, utiliza el concepto de «morfogénesis de la familia» para indicar que el cambio de las formas fami- 
liares es reflejo de complejos procesos de interacción en el tiempo entre actores y estructuras socioculturales. Habla en todo momento de cambios y transformaciones y no de crisis ni disolución de la familia en la sociedad actual.

La pluralización de las formas familiares es un fenómeno complejo que debe ser afrontado con un cuadro teórico y operativo de relativa complejidad, como respuesta a impulsos objetivos y subjetivos, locales y globales, de diferenciación e integración, y como expresión de la creciente subjetivización de los estilos de vida. Esta flexibilidad que la familia ha mostrado ante los efectos ambientales es reflejo de la capacidad que tiene para introducir las transformaciones externas en el interior de las relaciones de reciprocidad por las que se rige su cotidianidad.

Dados los profundos cambios y las repercusiones que los mismos tienen en todas las esferas sociales, Donati se pregunta, en primer lugar: ¿qué es o qué significa hacer familia? La cuestión previa es entender y analizar la naturaleza de los fenómenos familiares para, posteriormente, tratar de argumentar: jpor qué existe la familia?, ¿cómo se organiza?, ¿cómo cambia? y ¿cuál es el futuro de la familia?

Por todo ello, la familia debe ser considerada desde un punto de vista relacional. El enfoque relacional aplicado a la sociología de la familia es lo que hace particular a esta obra, puesto que implica leer todos los fenómenos desde una dimensión familiar, teniendo en cuenta el papel que la familia juega en el conjunto de la sociedad.

La familia contemporánea está sujeta a un proceso profundo de morfogénesis social, que redefine sus dos ejes principales: las relaciones de género y las relaciones de genitorialidad o entre generaciones. En cuanto a la relación de género, la familia es el sistema relacional que conecta los sexos entre sí, en el conflicto y en la solidaridad, estructurando la identidad y los roles que se consideran apropiados a los dos géneros. En cuanto a la relación intergeneracional, la familia es una relación única, donde conviven las generaciones como "forma social generativa» que genera generaciones pues la familia debe entenderse dentro de la red de parentela y no como un equivalente a la mera cohabitación.

La característica que define el sentido relacional de la familia es el hecho de crear ligámenes significativos entre las personas que comparten un proyecto de vida guiado bajo principios de solidaridad, don, equidad, amor, etc. A partir de estos elementos, la familia se configura determinante de la mediación social en la sociedad. Para Donati, no se está en familia con la sociedad, sino que se está en sociedad con la familia, en el sentido de que la familia siempre media el obrar social. Por este motivo, la familia debe ser tenida en cuenta tanto desde un punto de vista interno como externo.

No obstante, el problema surge en el modo de observar esta realidad, observar y comprender la relación que se sucede como dimesión estructural (de ligamen) y como dimesión simbólica (de referencia). Para dar un significado a todo, Donati se sirve del enfoque relacional que permite conocer las conexiones, los significados y los efectos que se producen en el interior de la familia. Abarcar esta tarea supone comprender la complejidad del término familia, pues no es un concepto reducible a una sola definición.

Tomando como referencia la confrontación que matiene Donati con Niklas Luhmann, la familia, como tipo particular de praxis social, tiene una sustancia que la define como tal, ser relación social plena, supraindividual y suprafuncional, que la convierte en un fenómeno social sui generis, original y originario, como relación primordial en sentido filogenético y ontogenético. Indudablemente, implica «asumir la familia como requisito primero y fundamental respecto a las posteriores posibilidades de hacer socie- 
dad». La familia es un fenómeno que implica, por lo menos potencialmente, todas las dimensiones de la vida: biológica, psicológica, social, cultural, económica, legal, política. Es un nexo fundamental que hace del individuo una persona humana, un ser en relación.

Esta caracterización de la familia, le permite a Donati justificar la hipótesis de que, a pesar de la morfogénesis de la familia, es el único lugar donde se puede dar solución a los problemas de la sociedad actual. El instrumento de actuación es la reciprocidad de las relaciones, enmarcadas en el cuidado y en la autoridad, en el don y en el amor.

Por el contrario, Niklas Luhmann desarrolla otra hipótesis. La familia es una realidad cambiante, sujeta a fases de evolución que suponen transformaciones de las funciones y las estructuras. La familia es un sistema de comunicación con unas funciones propias, un propio primado funcional, que es coincidente con la orientación a la totalidad de la persona mediante la obligación de la comunicación. Esto significa que en familia todo es comunicación. Y es la densidad comunicativa que se genera en la interacción familiar la que produce elevadas tensiones en las familias modernas.

Para Luhmann, las personas son entendidas como puntos de referencia de la comunicación, mientras que la familia pierde el rol decisivo que había mantenido en los sistemas sociales y pasa a ser mera interacción social. La familia pierde el rol tradicional de subsistema social, porque, según y desde su punto de vista, las familias, en las sociedades actuales, ya no realizan funciones vitales para el sistema social de referencia y no se concibe, por tanto, como agente de socialización.

Tal y como entiende Donati la sociedad y la familia, los planteamientos son contrapuestos. Ante esta pérdida de relevancia y centralidad de la familia de la lectura de Luhmann, Donati defiende que la familia como grupo e institución social, constituye una forma social con estructura propia, organización y funciones especializadas, al tiempo que es subsistema social integrado en el más amplio sistema social. Y esta doble posición en el sistema social es lo que le permite ser protagonista de la mediación entre lo humano y lo no humano, la distinción entre naturaleza y cultura y la diferenciación entre lo público y lo privado.

Según Donati, incomprensiblemente se ha afirmado la pérdida de funcionalidad de la familia, sin querer tener en cuenta su esencia misma. Lo que sí se afirma es la transformación de las formas de mediación: la familia es de vital importancia para establecer el éxito o fracaso de las generaciones en el subsistema educativo, en el subsistema económico, en el subsistema político. Comprender, analizar y observar esta red de relaciones es el punto de referencia para conocer las condiciones de bienestar y explicar los factores y causas de la desigualdad social en las sociedades actuales.

No obstante, las formas de mediación familiar no pueden reducirse a una. Se interseccionan tres tipos de mediación en la familia: entre géneros, entre generaciones y la propiamente de parentela. La familia, en cuanto sistema de relaciones particulares, está condicionada por los ambientes sociales, $\mathrm{y}$ tal condicionamiento se reintroduce en el interior de las propias mediaciones. Se denomina, por Donati, la familia autopoiética, en cuanto a que reproduce en su interior comunicaciones y relaciones. La sociedad actual determina, en gran medida, el propio modo de estar en la familia.

Las relaciones que se producen bajo principios de reciprocidad y el código simbólico del amor permiten que la familia busque soluciones a los problemas y desafíos de los demás subsistemas. Es, por tanto, un espacio social único, que dispone de los mecanismos e intrumentos oportunos para releer los fenómenos sociales en perspectiva familiar. 
La familia es, por lo tanto, indispensable para la realización personal y la creación de una buena vida civil. Cumple la función de socialización en cuanto sujeto de mediaciones, entendidas, en su conjunto y complejidad, bajo la perspectiva relacional. Sin embargo, y si recordamos las cuestiones que se plantea Donati en este manual, las contradicciones que se registran en las relaciones y en las mediaciones sitúan a la familia como punto de referencia y sujeto determinante e impulsor de soluciones.

La paradoja público-privado, la familia como mediación entre los empujes individualistas y las instancias socializadoras, o las nuevas formas de naturalización y culturización de la familia, son los retos y desafíos que se deben de afrontar para comprender en su conjunto la realidad familiar.
Para ello, Donati se sirve de una brújula relacional, incorporando el carácter suprafuncional de las relaciones y las relaciones familiares propiamente dichas. La familia relacional no puede ser sustituida, dada la función de mediación social que cumple y que la caracteriza como grupo e institución social. En el enfoque relacional, que incorpora todos los subsistemas sociales, la familia es el sujeto social crucial. La perspectiva de Donati defiende una lectura de la realidad social desde dimensiones familiares: contemplar la sociedad desde la familia, como fenómeno relacional que comprende, más allá de relaciones estructurales, las relaciones simbólicas.

Sonia Pagés Luis Universidad de Granada Departamento de Sociología 